\title{
Eine Kunst wie Bärlauchblätter und Walderdbeeren
}

\section{Felix Schürch}

Dr. med., Facharzt für Allgemeine Innere Medizin, Mitglied FMH

Das Aargauer Kunsthaus zeigt in der Ausstellung "Kunst im Verborgenen» rund 200 Werke von Künstlerinnen und Künstlern der "Art Brut». Für Museumsleute und Kunsthistoriker ist der Begriff "Art Brut» so etwas wie eine Diagnose. Als Mediziner benutze ich für die Krankheiten Klassifikationssysteme wie das ICD oder das DSM mit subtilen Unterteilungen und Nummerierungen. Die Kunsthistoriker möchten verständlicherweise im Bereich der künstlerischen Produktion ebenfalls Ordnung schaffen. Dieses Unterfangen ist nicht ganz leicht: Denn genau wie in der Medizin werden viele Begriffe in Frage gestellt und immer wieder neu definiert. Und genau wie in der Medizin bezeichnen böse Kritiker diese ganzen Einteilungen als hilflose Versuche der Schubladisierung - weltfremd und lächerlich.

Beim Etikett «Art Brut» (franz. rohe, ungeschliffene Kunst) beginnen die Definitionen allesamt mit negativen Kriterien: Die Künstlerinnen und Künstler haben keine akademische Ausbildung. Sie besitzen weder das Diplom einer Kunsthochschule noch die Auszeichnung einer staatlichen Kulturförderung. Sie gehören keiner stilbildenden Künstlervereinigung an. Sie bleiben gesellschaftlich erfolglos und leben in psychiatrischen Kliniken, Gefängnissen oder Heimen. Ihre Kunst

\section{Die Werke der «Art Brut» fesseln uns.}

ist ungehobelt und unverständlich. Und doch: Die Werke der «Art Brut» fesseln uns. Die Faszination dieser Werke lebt von ihrer Unmittelbarkeit und ihrer ungeschliffenen Originalität. Ich erlebe diese Kunst so ähnlich wie in der Küche den frisch gepflückten Bärlauch im Frühling und die Walderdbeeren im Sommer.

Der Weinbauer und Künstler Jean Dubuffet (1901-1985) - er prägte den Begriff der «Art Brut» - war ein Bewunderer und Sammler von Werken von Leuten, «die durch die Kunstkultur keinen Schaden genommen haben». Oft wurde Dubuffet auf seinen Reisen in der Schweiz fündig, nicht selten durch die Vermittlung durch Psychiater und Klinikdirektoren, die ihrerseits ein Auge für die Kreationen der Menschen in ihrem Umfeld hatten.

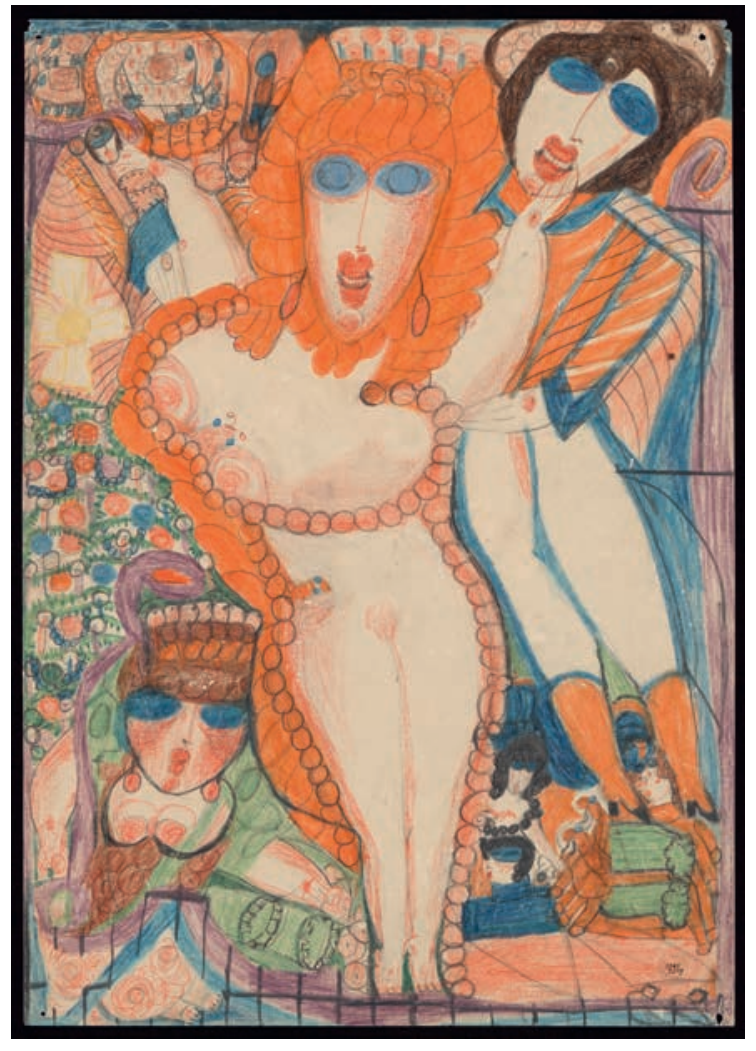

Aloïse Corbaz, Napoléon portant une reine au corps cerné de perles, ca. 1946-1947

Farbstift auf Papier, 59,5 $\times 42 \mathrm{~cm}$

Collection de l'Art Brut, Lausanne

Foto: Olivier Laffely, Atelier de numérisation - Ville de Lausanne 
Das Kunsthaus Aarau zeigt nun Werke von gut zwei Dutzend Künstlerinnen und Künstlern. Ihnen allen gemeinsam ist - zusätzlich zum Label "Art Brut» - das Herkunftsland «Schweiz». Drei von ihnen möchte ich beispielhaft kurz vorstellen. Im Eingangsbereich der Ausstellung begegnen wir Aloïse Corbaz (1886-1964), respektive ihren prallen Damen und deren männlichen Verehrern. Die rosa Körper, die blauen Augen und die Attribute sind zu spannungsvollen Kompositionen vereint. Die Künstlerin benutzte für ihre Farbstift-

\section{Allen Künstlern gemeinsam ist - zusätzlich zum Label "Art Brut» - das Herkunftsland «Schweiz».}

zeichnungen häufig Packpapier und nähte manchmal zwei Bögen zusammen, um das gewünschte Grossformat zu erhalten. Seit ihrem 32. Altersjahr lebte Aloïse Corbaz in Anstalten in Lausanne; die Diagnose lautete "Dementia praecox". Aloïse gilt heute - wie Adolf Wölfli, von dem in Aarau ebenfalls viele Werke präsentiert werden - als herausragende Vertreterin der "Art Brut» in der Schweiz.

Aus dem Berner Oberland stammt Heinrich Anton Müller (1865-1930). Bereits 1922 erwähnte der deutsche Psychiater Hans Prinzhorn in seinem Grundlagenwerk «Bildnerei der Geisteskranken» diesen Künstler. Müller war ursprünglich Winzer in der Nähe von Vevey. Mit 37 Jahren wird er in die "Irrenanstalt» in Münsingen bei Bern eingewiesen, hier bleibt er bis an sein Lebensende. Er hat Wahnideen, seine Bilder und Zeichnungen signiert er bisweilen mit «Gott». Im Garten der Klinik montiert er selbsterfundene Maschinen aus Drähten und Stofffetzen, daneben fertigt er Zeichnungen an. Sein Interesse gilt Gesichtern, die er ähnlich wie die Kubisten aus verschiedenen Perspektiven darstellt. Auf einer seiner Zeichnungen blickt uns stumm und staunend eine menschliche Figur entgegen, ihre Kontur ist amöbenhaft ausgefranst. Insekten krabbeln auf der Haut umher und bedrohlich windet sich eine Schlange auf der linken Seite in die Höhe. Als Betrachter werden wir hier Zeuge eines beängstigenden Auflösungsprozesses.

Fast ungegenständlich sind die Arbeiten von Gaston Teuscher (1903-1986). Wenn ich mir die Biografie dieses Künstlers vor Augen führe, sehe ich einen Weltenbummler und begabten Allrounder vor mir. Teuscher macht Reisen durch ganz Europa, den Lebensunterhalt bestreitet er als Französischlehrer und Gymnastikinstruktor, später wird er Lehrer in der Schweiz. Mit 71 Jahren beginnt er unvermittelt seine künstlerische Produktion. Leere Zigarettenpackungen, Papierservietten und Packpapier benützt er als Mal-

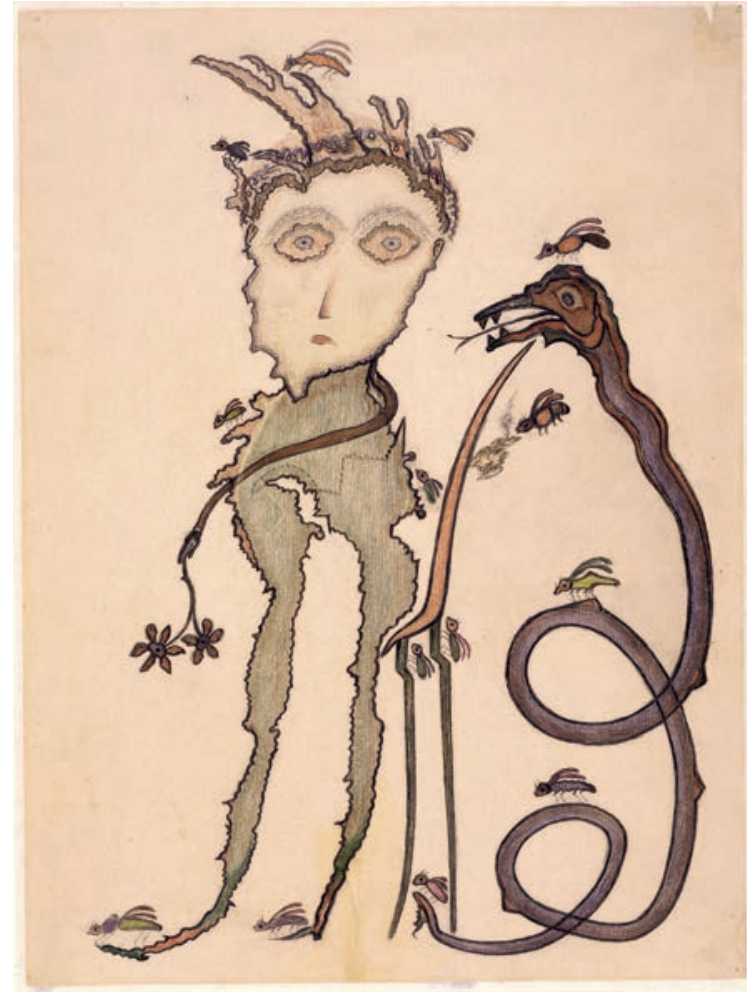

Heinrich Anton Müller, sans titre, zwischen 1925 und 1927 Farbstift auf Zeichenpapier, $57.5 \times 42.5 \mathrm{~cm}$

Collection de I'Art Brut, Lausanne

Foto: Claude Bornand

grund, auf dem er mit Tinte, Kugelschreiber und Bleistift Figuren und Gesichter zeichnet. Seine Kompositionen sind im wahrsten Sinn des Wortes vielschichtig, manchmal benützt er sogar ein Feuerzeug, um die Blätter am Schluss mit einem braunschwarzen Schatten zu überdecken.

Zur Ausstellung hat die "Collection de l'Art Brut" in Lausanne ein kleines Buch herausgegeben mit farbigen Abbildungen, einer Einführung ins Thema und Angaben zu den Künstlerinnen und Künstlern. Schon

Ihre Werke sind ein beglückendes Geschenk für jeden, der sich auf die ungewöhnlichen Kreationen und ihre geheimen Botschaften einlässt.

anhand der wenigen biografischen Angaben können wir uns gut vorstellen, dass es diese Menschen ihrer Umgebung mit ihrem Verhalten nicht immer ganz einfach gemacht haben. Ihre künstlerischen Werke sind jedoch ein beglückendes Geschenk für jeden, der sich auf die ungewöhnlichen Kreationen und ihre geheimen Botschaften einlässt. 